\section{A ERGOLOGIA NA ARGÉLIA}

THE ERGOLOGY IN ALGERIA

Fyad Abderrahmane ${ }^{1}$

Resumo O depoimento revela aspectos das relações de trabalho, focalizando principalmente nos direitos do trabalho de proteção aos riscos e à saúde. Além disso, apresenta elementos históricos da colaboração entre professores-pesquisadores da Universidade de Oran, na Argélia, e professores-pesquisadores do Departamento de Ergologia da Universidade de Provence, na França, para a implementação de projetos e formação de médicos do trabalho.

Palavras-chave trabalho; relações de trabalho; Argélia; ergologia.
Abstract The testimony reveals aspects of labor relations, focusing primarily on labor rights protection and health risks. Maneover, it presents historical elements of collaboration between teachers and researchers at the Univesity of Oran, Algeria, and research faculty of the Departement of Ergology University of Provence, France for project implementation and training of occupational physicians.

Keywords employment; labor relations; Algeria; ergology. 
Falar da ergologia na Argélia equivale a evocar o histórico da descoberta da 'postura de análise' pertencente a pessoas que cruzaram o caminho do professor Yves Schwartz. Teremos que desenvolver mais adiante essa alusão, pois ela se impõe no mesmo nível dos primeiros ergônomos argelinos formados pelo grande mestre Alain Wisner, no Conservatoire National des Arts et Métiers (CNAM), somente para fazer referência a algumas sementes lançadas ao acaso nesses domínios.

Mas, antes, eis o que se impõe igualmente pertinente. Em 1971, a Argélia, mergulhada em uma amálgama de reformas voluntaristas em todos os domínios, inicia uma reforma do ensino superior com a abertura de muitas universidades públicas e com acesso gratuito. Simultaneamente a essa medida qualificada como 'de progresso' e, sem dúvida, bastante apreciada na época, as ciências sociais, em especial o ensino da filosofia, são acusadas de responsáveis, por um lado, pelo desaparecimento de cátedras de filosofia e, por outro, pela vertiginosa transição, sem precedentes, do francês, como língua de ensino, para o árabe. E o coletivo do professorado arabófono não se encontrava, na época, suficientemente preparado para fazer face a tal desafio. Essa breve invocação de um momento histórico de desenvolvimento das universidades argelinas, que comporta certas estigmatizações, explica em parte o acolhimento e a implementação tímida de um pensamento ergológico propriamente dito.

Entre os paradoxos argelinos, e sempre em relação com a política voluntarista dos seus dirigentes, a facção que vai acolher os desenvolvimentos universais do pensamento sobre o trabalho emergerá, modestamente, e com toda a clareza, não em um domínio acadêmico clássico, como na França, mas antes em um ambiente de formação encorajada em torno da preservação da saúde do 'trabalhador argelino', ícone da gestão 'socialista das empresas de 1973'. São, portanto, as faculdades de medicina que vão se encarregar de reacender a vivacidade da universidade desvastada pela reforma.

Será, pois, necessário esperar pelo início dos anos 2000 para que os primeiros contatos e trocas tenham lugar entre 'praticantes da saúde no trabalho' (da Argélia), por um lado, e os 'praticantes do pensamento crítico sobre o trabalho humano' (da França, da Tunísia...), por outro, nas suas diversas ligações com o econômico, o político, a saúde e a orientação do trabalho.

\section{Qual é o estágio atual da ergologia na Argélia?}

A melhor ilustração, também para sermos fiéis a essa 'disciplina', é dar uma imagem da situação, no lugar de cedermos à tentação de apresentar números. Essa ilustração diz respeito ao encontro de uma diretora de recursos humanos (DRH) e de um médico do trabalho, pertencentes a um Centro 
Hospitalar Universitário. A DRH chama-se Aída. Este nome lembra, a alguns, a designação de uma peça teatral e, localmente, significa 'regresso ou aquela que regressa'.

Com efeito, a DRH acompanha os seus assalariados à visita médica (no médico do trabalho) por incumbência do seu empregador, uma prática recente na Argélia: a empresa que designamos 'Oran 31' opera, na prática, como sucursal de uma empresa-mãe espanhola, e proporciona uma logística técnica no fornecimento de força de trabalho temporária à empresa realizadora do grande projeto de tramway de Oran. ${ }^{2}$

É, portanto, durante uma entrevista para conhecer as reais necessidades da Oran 31, para melhor satisfazer às suas obrigações profissionais, que o praticante em saúde do trabalho descobre uma realidade de gestão de força de trabalho em seu país até então desconhecida e inesperada. As suas referências (normas antecedentes), ao nível jurídico, estão completamente fora do lugar. O contrato de trabalho que ele conhecia, seguro e dotado de múltiplas garantias e proteções, não é mais usual. A Oran 31 impõe aos seus assalariados um Contrato de Trabalho Determinado (DDI) mais curto e jamais praticado no país: dez dias, longe de atingir os noventa dias eventualmente reembolsáveis, e pratica demissões em massa até então sem precedentes na Argélia.

Nessas condições, o recurso à medicina do trabalho e a inclusão da declaração prévia à segurança social aparecem, em um novo contexto, como vestígios de uma nova etapa reelaborada, porque a Oran 31, pautando pelo princípio de sacrifício face às obrigações regulamentares do código de trabalho local, não esconde a sua política de criação de uma espécie de reserva de desempregados que a qualquer momento pode substituir os seus assalariados em caso de acidentes ou inatividade. A empresa aplica, assim, 'uma gestão do trabalho ao estilo americano': trocando tudo somente pela contraparte que lhe é válida, ou seja, os assalariados em elevado número, portanto sem correspendência com o que ela aplica no setor da construção civil.

Com efeito, trata-se aqui de um 'retorno' ao modo de gestão da 'força de trabalho' com novas regras evocando um capitalismo desregrado. E isso lembra o que se passou nos países denominados 'de mercado e de direito', onde a norma que rege o direito do trabalho protege contra o abuso e o arbítrio e fixa um quadro para uma possível análise da 'atividade de trabalho' como ponto de apoio a uma possível transformação das condições de trabalho.

Eis, pois, como descobrimos um campo vasto de reflexão ergológica, inédito na Argélia: um país que está sob pressão progressiva da internacionalização das economias mundiais, rumo a modelos de gestão laboral já conhecidos em países ditos 'emergentes' como a Índia, a Argentina e, naturalmente, o Brasil. 
Apesar de tudo, essas novas regras e esse novo tipo de contrato e de subordinação do trabalho não estão generalizados. O antigo setor nacionalizado, dito estatal, se beneficia ainda de regras coerentes em matéria de proteção, representação etc. Esse é o caso das administrações de função pública, hospitais e setor do ensino.

A persistência das modalidades de emprego com contrato por tempo indeterminado coexiste, atualmente, com a introdução, nas mesmas instituições, da celebração de contratos 'frágeis' e revogáveis pelo empregador, assim como é o próprio Estado ou as instituições a ele adjacentes. Os outros setores, como a agricultura e o setor dito informal, estão sobretudo sob influência de normas costumeiras ou normas reconstituídas.

O estudo sobre o trabalho informal (Fyad, 2008), que levamos a cabo junto dos 'parâmetros humanos' 3 na cidade de Oran, na Argélia, evidencia as normas e os valores (debate das normas e dos usos de si para si e usos de si para os outros) em jogo no decurso desses tipos de atividades humanas e sociais. A descrição ou referência a essas diferentes modalidades na questão da subordinação do trabalho provam a existência de um campo vasto para a perspectiva ergológica na Argélia.

\section{De que forma se pode assumir tal postura na análise de atividade humana na Argélia?}

Para responder a essa questão, é importante, em primeira instância, retornar ao assunto da formação de eventuais competências nesse domínio ou em domínios referentes a outras disciplinas epistêmicas afins. No caso da Argélia, três domínios podem ser identificados:

- A formação dos médicos do trabalho - Nesse domínio, os resultados quantitativos são apreciáveis, uma vez que o país pode contar incontestavelmente com uma das taxas mais elevadas no mundo de médicos para prestar assistência aos assalariados em atividade. Todavia, essa taxa, apesar de elevada, não dispensa a necessidade de formação em matéria de proteção de saúde no trabalho, como instrumento para elevar a eficácia e o desempenho no trabalho.

- A formação de ergonomistas - Evocamos, no início deste texto, a formação dos primeiros ergonomistas no Conservatoire National des Arts et Métiers (CNAM), sob a direção do professor Alain Wisner, nos anos 1970. Essa experiência não obteve êxito e não alcançou qualquer efeito multiplicador. Algumas dessas competências foram, mesmo assim, usadas no plano internacional.

- A descoberta da ergologia - Naquilo que se poderia qualificar como uma preocupação em relação à conjugação de forças intelectuais para uma me- 
lhor abordagem do trabalho, os 'herdeiros' de várias ações não concretizadas conseguiram, com reconhecimento das falhas passadas, instituir uma organização internacional designada Association Internationale Travail Santé Environnement en Méditerranée (AITSEM) na Tunísia, em 2004. O objetivo declarado dessa associação internacional é de promover o ensino à distância sobre a saúde, o trabalho e o ambiente ao longo do Mediterâneo.

É nessa ocasião que, pela primeira vez, houve o encontro com o professor Yves Schwartz, fundador da ergologia com uma postura 'paradigmática' nova (humildade, rigor e ambição), para uma análise do trabalho para o transformar. Nos esforços para articular ações de formação da universidade e as necessidades das empresas locais, foi criado, na Argélia, um diploma de pós-graduação especializado denominado diplôme de post graduation spécialisé (DPGS), o que foi possível graças à colaboração entre as faculdades de medicina de Tlemcen e de Oran. O conteúdo essencial do referido diploma é 'gestão do risco da saúde ligada ao trabalho e ao meio ambiente industrial'4.

Esta formação foi realizada duas vezes, em 2004/2005 e em 2007/2008. E o Departamento de Ergologia de Aix-en-Provence 5 desempenha, evidentemente, um papel decisivo, implantando, de forma mais energética, a pers-

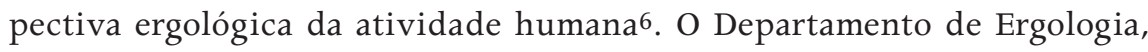
portanto, no âmbito de uma convenção interuniversitária, assegura alguns módulos consagrados à descoberta da abordagem ergológica e à análise da atividade de trabalho a partir dessa postura. E essa colaboração continua, atualmente, através do alargamento para a Associação Saúde Trabalho Interempresas (Asti), em Toulouse, França (são pesquisadores franceses colaboradores neste projeto: G. Guérin, F. Daniélou e M. Brahim-Brahim), que intervém na formação em ergonomia/ergologia7 na cidade universitária de Tlemcen - que fica no oeste da Argélia -, a um grupo de cerca de vinte estudantes argelinos.

Em geral, podemos considerar que, a partir desses convênios interuniversitários, a totalidade das noções em ergologia foi partilhada por cerca de cinquenta praticantes de saúde e prevenção por meio de trabalho industrial na Argélia. Com efeito, entre as formações mais destacáveis (ao nível de mestrado), dois psicólogos e dois médicos de trabalho argelinos foram formados em Aix-en-Provence, no âmbito desses mesmos convênios.

No plano internacional, a Argélia esteve representada por um docente, a título não oficial, no colóquio "Ergologia, Trabalho e Desenvolvimento" e na criação da rede franco-lusófona que o Centro de Investigação de Ergologia para o Desenvolvimento (Cied) 8 e a Universidade São Tomás de Moçambique organizaram em Maputo, em junho de 2007. 


\section{A parceria operacional}

No âmbito da criação do DPGS, intitulado "Gestão do risco da saúde ligada ao trabalho e ao meio ambiente industrial", conforme citamos anteriormente, foi igualmente instituído o departamento denominado 'Instituto de Ergologia'. Metade dos engenheiros e médicos que seguiram este ensino provinha da empresa nacional argelina de hidrocarbonetos, a Sociedade Nacional de Transporte e Comercialização de Hidrocarbonetos (Sonatrach).

As sessões de formação, teóricas e práticas de seiscentas horas, estavam abertas a quadros em atividades e culminavam com a produção de um trabalho de tese proposto por cada candidato. Dessa forma, o DPGS foi concebido como um certo tipo de formação contínua para agentes e quadros da empresa, oferecido gratuitamente para os participantes. Em contrapartida, inteiramente financiado pela empresa beneficiária.

A contribuição - bastante original e enriquecedora - dos docentes ${ }^{9}$ de Aix-en-Provence cobria cerca de cem horas do total das horas previstas para os módulos. E em relação ao ano universitário 2010/2011, o Departamento de Ergologia participa mais uma vez na docência, no quadro de mais um DPGS lançado pela Universidade de Tlemcen.

\section{Conclusão}

Este testemunho foi uma tentativa de demonstração das ligações que existem entre as vontades no mundo do trabalho do homem particular e sua tradução modesta, contudo laboriosa, em substância nos fatos. Trata-se, pois - para nos servirmos de um dos conceitos emblemáticos na ergologia -, de esforços de 'renormalizações' da nossa parte, com a finalidade de transformar uma visão, que julgamos pertinente, em projeto de vida e de cooperação concreta. Por isso, podemos concluir que tal engajamento, sendo uma espécie de 'microinvestimento', leva à crença, no ensinamento da ergologia, de que 'nada se ganha por antecipação'. 


\section{Notas}

1 Médico do trabalho e professor na Universidade de Oran, Argélia. Colabora em diversos projetos no Departamento de Ergologia da Universidade de Provence, França. <abfyad@yahoo.fr>

Correspondência: Département d'Ergologie, Université de Provence, 29, Avenue Robert Schuman, 13621, Aix-en-Provence, Cedex 1, França.

2 Oran é a segunda maior cidade da Argélia. É uma cidade portuária e universitária que tem mais de dois milhões de habitantes. Encontra-se no mar Mediterrâneo, a oeste do país.

3 Esta é a designação usada para se referir aos guardas eventuais de veículos nos espaços públicos, ruas e artérias da cidade de Oran.

4 O DPGS é dirigido pelo professor Fyad Abderrahmane, da Universidade de Oran.

5 Université d'Aix-Marseille. Avenue Robert Schumann - Aix-en-Provence - 13100, França.

6 Cf. adiante "A parceria operacional".

7 DPGS de ergonomia, dirigida pelo professor Taleb Abdesselam, da Universidade de Tlemcen.

8 Centre d'Investigation Ergologique pour le Développement (CIED). Avenue Tomas Ndunha, n. 95, $1^{\circ}$ andar, flat n. 3, Maputo, Mozambique.

9 Professores participantes: Yves Schwartz, Rénato di Ruzza, Rémy Jean e Pierre Trinquet.

\section{Referências}

ABDERRAHMANE, Fyad. O trabalho informal: uma abordagem ergológica. Revue Laboreal, v. IV, n. 1, jul. 2008. Disponível em: $<$ http://laboreal.up.pt $>$ (Texto em português).

Recebido em 22/03/2011

Aprovado em 17/06/2011 